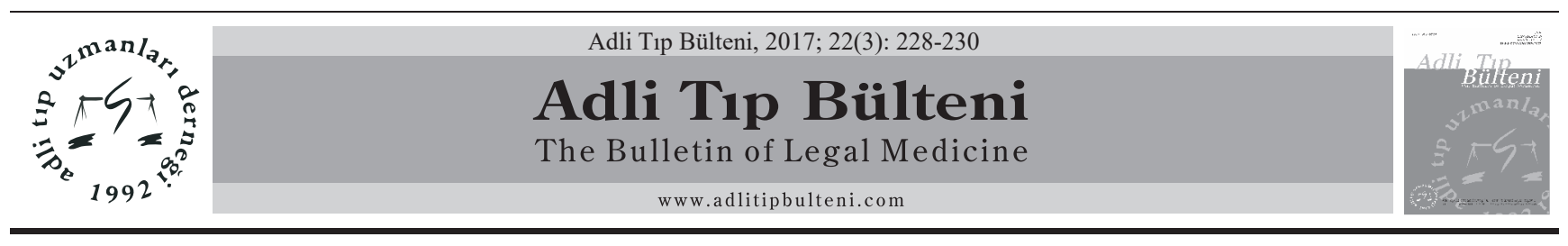

OLGU SUNUMU / CASE REPORT

doi: 10.17986/blm.2017333104

\title{
Metanol Zehirlenmesi: Olgu Sunumu
}

\section{Methanol Toxicity: Case Report}

\author{
Hümeyra Yıldırım Can', Halil Kırbıyık ${ }^{2}$ \\ ${ }^{1}$ Balıkesir Devlet Hastanesi Göz Hastalıkları Kliniği, Balıkesir \\ ${ }^{2}$ Balıkesir Devlet Hastanesi İç Hastalıkları Kliniği, Balıkesir
}

\begin{abstract}
Özet
Metil alkol endüstride yaygın olarak kullanılan bir alkoldür. Yasadışı olarak ta kaçak üretilen içkilerde kullanılmaktadır. Metil alkol zehirlenmesi yüksek oranda ölüm riski taşıyan metabolik asidoza, görme kaybına ve bazal gangliyon hasarına neden olan klinik bir durumdur. Tedavide metabolik asidozun düzeltilmesi için bikarbonat takviyesi, antidot verilmesi ve hemodiyaliz uygulanır. Bu çalışmada metil alkol zehirlenmesi olarak tedavi edilen, göz polikliniğine ani görme kaybı nedeniyle başvuran ve 48 saat önce içki içtiğini bildiren 45 yaşında bir erkek olgu sunulmuştur.

Anahtar Kelimeler: Metil Alkol; Zehirlenme; Görme Kaybı.
\end{abstract}

\begin{abstract}
Methyl alcohol is an alcohol commonly used in the industry. It is also used in illegally produced drinks. Methyl alcohol poisoning is a clinical condition that causes vision loss, basal ganglion damage and metabolic acidosis with high risk of death. Bicarbonate supplementation, antidote administration and hemodialysis are applied to correct metabolic acidosis. We present in this study a 45 -year-old male who was admitted to the Eye Polyclinic with sudden visual loss and was treated as methyl alcohol poisoning due to drinking 48 hours ago.

Keywords: Methyl Alcohol; Intoxication; Visual Loss.
\end{abstract}

\section{Giriş}

Metanol odunun damitılmasiyla elde edilen bir alkoldür ve organik çözücü özelliğinden dolayı endüstride kimyasal çözücülerin çoğunda kullanılır. Oda sıcaklığında sıvı halde bulunan, renksiz, toksik bir maddedir. Metanol zehirlenmesi sıklıkla yasadışı yollarla üretilen içkilerin oral alımıyla oluşmakla birlikte kazara ya da intihar amacıyla da içilebilir (1). Daha nadir olarak deri ya da inhalasyon yoluyla da metanol zehirlenmesi gelişebilir (2).

Metanol kendisi çok toksik olmamakla birlikte vücutta alkol dehidrogenaz enzimi tarafından çok toksik metabolitlere dönüşür. Formaldehid ve Formik aside metabolize olan metanol yüksek anyon açıklı metabolik asidoza, bazal ganglion hasarına, retinal hasara ve optik sinir hasarına neden olur. Oluşan toksik formik asit mitokondrilerdeki sitokrom c oksidaz aktivitesini inhibe ederek hücresel hipoksiye neden olarak retinal ganglion hücrelerinde hasara neden olur $(3,4)$.

Metanol zehirlenmesinde bulgular sıklıkla oral alımdan 12-24 saat sonra ortaya çıkar. Bu gecikme metanolün toksik metabolitlerine yavaş metabolize olması ile ilgi-

Sorumlu Yazar: Uzm. Dr. Hümeyra Yıldırım Can Balıkesir Devlet Hastanesi Göz Hastalıkları Kliniği, Balıkesir E-mail: balikesirhumeyra@gmail.com

Geliş:20.10.2017 Düzeltme:04.11.2017

Kabul:08.11.2017 lidir. Hastada erken dönemde genelde görsel problemler karın ağrısı, vertigo, bulantı, kusma ve baş ağrısı olabilir. Geç dönemde tedavi edilmediğinde ise koma, körlük, gastrointestinal kanama, putaminal kanama ve ölüm gelişebilir. Görsel problemlerin bir kısmı düzelmekle birlikte kalıcı görme hasarı da gelişebilir.

\section{Olgu}

Olgumuz 45 yaşında erkek hastadır; her iki gözünde görme kaybı geliştiğini belirterek göz polikliniğine başvurmuştur. Her iki gözde görme 1mps düzeyinde pupiller middilate ve fundus görüntüsü doğal bulunmuş hasta kraniyal bir patoloji şüphesi ile nöroloji kliniğine konsülte edilmiştir. Yapılan nörolojik muayenesinde bilinç açık oryante ve koopere olduğu görülmüş herhangi bir patolojik reflekse rastlanmamıştır. Bilgisayarlı Beyin Tomografisinde, Diffüzyon MR ve MR kranial anjiografi de nöropatolojiye rastlanmadı. Hastanın detaylı öyküsü alındığında 48 saat önce içki (votka) içtiği öğrenildi. Hastanın ilk muayenesinde TA: 130/70 mmHg, Nb:72 /dk, Ateş: 36.6, Solunum: 16 /dk idi.

Hastanın laboratuar bulguları değerlendirildiğinde, Ph:7.34, PCO2: $30.9 \mathrm{mmHg}$, PO2: $90.6 \mathrm{mmHg}$, HCO3:18.2 mmol/L, Üre: $25 \mathrm{mg} / \mathrm{dl}$, Glukoz: $74 \mathrm{mg} /$ dl, Kreatinin: $0.64 \mathrm{mg} / \mathrm{dl}$, AST: $18 \mathrm{U} / \mathrm{L}$, ALT: $19 \mathrm{U} / \mathrm{L}$, T.Bil:1.98 mg/dl, D.Bil: $0.61 \mathrm{mg} / \mathrm{dl}, \mathrm{Na}: 132 \mathrm{mmol} / \mathrm{L}$, 
Ca: 1.10 mmol/L, Cl: 103 mmol/L idi. Tam kan sayımın-

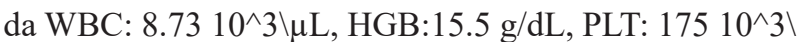
$\mu \mathrm{L}$ olduğu tespit edildi. Hastanın ikinci gün yapılan kontrol oftalmolojik muayenesinde bilateral görme kaybının ilerlediği sağ göz vizyon 1 șik pozitif düzeyinde, sol göz vizyon 1 șik pozitif düzeyinde olduğu tespit edildi. Pupillerin middilate olduğu, 1şık refleksinin kaybolduğu fundus muayenesinin doğal olduğu görüldü.

Hastada gelişen ani görme kaybı, içki içme öyküsü, $\mathrm{Ph}$ ve bikarbonat değerlerinin metabolik asidoz açısından sinırda olması nedeniyle (ph:7.34, HCO3:18.2 mmol/L), olgu metanol zehirlenmesi olarak değerlendirildi. Ancak hastanın kan metanol düzeyine bakılamadı. Hastaya medikal tedavi olarak bikarbonat takviyesi, hemodiyaliz ve antidot tedavisi (4 ampul fomepizol) uyguland.

Hastanın 45 gün sonraki kontrol muayenesinde sağ vizyon 0.7 sol vizyon 1 mps düzeyinde idi. Hasta sol gözünün geçirilmiş eski bir travma nedeniyle 25 yıldır az gördüğünü ifade etti. Fundus muayenesinde sağ da hafif tilte temporali soluk optik disk, solda soluk optik disk mevcuttu. Hastanın 9 ay sonraki kontrol muayenesinde görme düzeyleri sağ göz 0.7 sol göz $1 \mathrm{mps}$ düzeyindeydi. Özellikle gün 1şığında fotofobi nedeniyle görmekte zorluk yaşadığını ve akşamları ve loş 1şıkta daha rahat gördüğünü ifade etti. Renk görme muayenesi için ishiara testi kullanıldı; ancak hasta renkleri ayırt edemedi. Hastanın 9 ay sonraki renkli fundus fotoğraflarında optik disk solukluğu (optik atrofiye gidiş) görülmektedir. (Resim 1 ve Resim 2). Hastanın kontrol nörolojik muayenesinde EEG ve EMG ve Kraniyal MR bulgularında herhangi bir patoloji tespit edilmedi.

\section{Tartıșma}

Metil alkol zehirlenmesi sıklıkla hastanın hastaneye geç başvurması ve bazen de teşhiste geç kalınmasından dolayı yüksek oranda ölüm riski taşımaktadır. Bazen öyküsü alınan hasta da en sık görülen semptom görsel (bula-

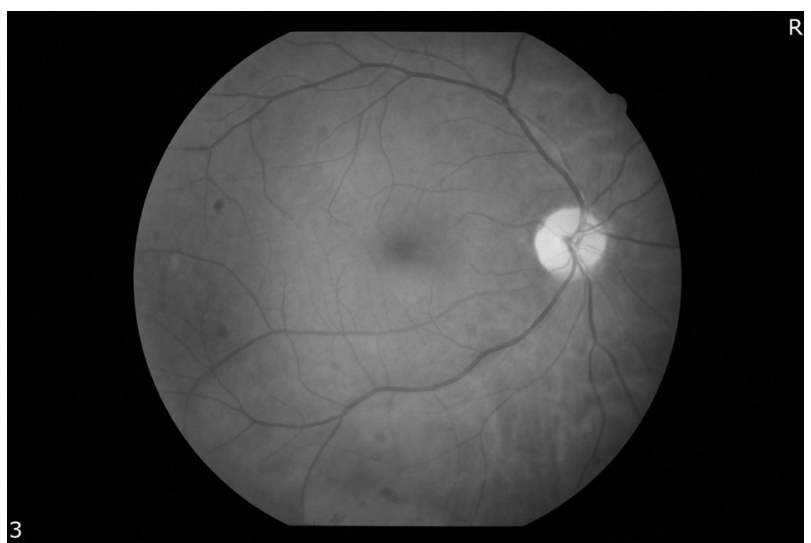

Resim 1: Sağ göz fundusta optik disk temporalinde belirgin solukluk görüntüsü nık görme, görme keskinliğinde azalma vb.) şikayetlerdir. $\mathrm{Bu}$ durumu, gastrointestinal şikayetler takip eder. Erken dönemde optik sinir normal görünebileceği gibi hiperemik de olabilir; 1 şı refleksinde zayıflama ya da tamamen kaybolması pupillerde dilatasyon görülebilir. Görsel semptomların çoğunluğu erken dönemde düzelmekle birlikte, görme kayıplarında kısmi düzelme ya da tam körlük gelişebilir $(5,6)$. Düzelen görsel yakınmaların bazen geç dönemde de yeniden kötüleştiği bildirilmiştir. Uzun dönemde hastalarda görme keskinliğinde azalma, görme alanında daralma, renkli görme kaybı ve optik atrofi gelişebilir. Geç dönemde herhangi bir görsel yakınması olmayan hastalarda bile OCT ve VEP bulgularında normal olmayan bulgular saptanabilir (6). Bizim olgumuzda geç dönemde optik diskte solukluk tespit edildiği, ayrıca hastada diskromotopsi ve fotofobi yakınması olduğu saptandı.

Metil alkol zehirlenmesinde tanıyı doğrulamak amacıyla metanol düzeyine bakmak gereklidir; ancak bu her zaman mümkün olmayabilir. Bu durumda hastanın bilinci açıksa içki içip içmediği sorgulanmalıdır. Bizim olgumuzda metanol düzeyine ne yazık ki bakamadık.

Metil alkol zehirlenmesinde tedavi metabolik asidozun düzeltilmesi, toksik metabolitlerin oluşumunu engellemek için antidot verilmesi, metil alkol ve toksik metabolitlerin kandan uzaklaştırılması için hemodiyaliz uygulamasını içermektedir (4). Prognozda hastanın ilk başvurduğu dönemdeki Ph düzeyi önemlidir (7,8). Ciddi asidoz ve koma kötü prognoza işaret ederken hastanın geldiği anda bilincinin açık olması ve hiperventilasyon yapabilmesi iyi prognoza işarettir $(8,9)$.

Metil alkol zehirlenmelerinin tedavisinde hastaya etanol uygulaması uzun yıllardır kullanılan bir tedavi yöntemidir. Etanolün alkol dehidrogenaza afinitesi metanolden 10 kat daha fazladır (10). Etanol alkol dehidrogenazın aktif kısmını kaplar ve toksik metabolitlerin oluşumununu engeller (5). Etanolün merkezi sinir sisteminde depres-

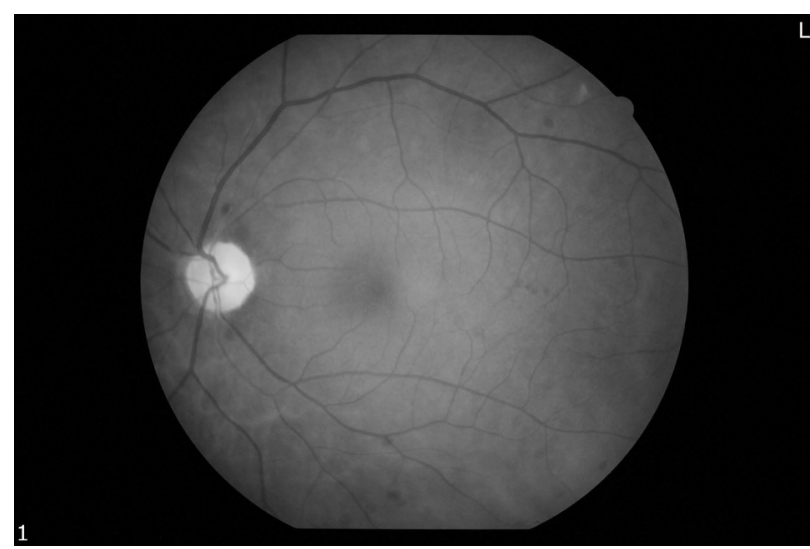

Resim 2: Sol göz fundusta atrofik optik disk görüntüsü 
yona neden olması ve kan düzeyinin takibinin zor olması nedeniyle bir diğer antidot olan fomepizol son y1llarda daha az yan etki ve etkinliği nedeniyle etanole göre daha fazla tercih edilmektedir. Fomepizol (4-methylpyrazol) metanole göre alkol dehidrogenaza afinitesi 1000 kat daha fazladır. Fomepizol çocuklarda kullanılabilir ve yan etkisi daha azdır ayrıca ilaç düzeyinin takibine gerek yoktur (11). Fomepizolün maliyeti etanole göre daha yüksektir ve temini her zaman mümkün olmayabilir. Metil alkol zehirlenmesinde etanol ve fomepizol arasında yoğun bakımda kalış süresi ve hemodializ ihtiyacı arasında bir fark bulunamadığını savunan yayınlar olmasına rağmen, tam tersine fomepizolün hemodializ süresini kısalttığını belirten yayınlar da vardır $(8,12)$. Fomepizol daha az yan etkiye neden olması ve hemodializ ihtiyacını azaltması nedeniyle ilk tercih edilen antidot olmalıdır. Yapılan bir çalışmada, $100 \mathrm{ml}$ kanda metanol oranı 0-826 mg arasındaki düzeylerinde tespit edilmiştir. En yaygın makroskopik ve mikroskobik bulgular, beyin ve optik sinirde iskemik değişiklikler, serebral ve serebellar kanama ile akciğer ödemi idi. Putaminal nekroz ve kanama, beyin sapında peteşial kanamalar, talamik ve hipotalamik kanama ile miyokardiyal akut iskemik değişiklikler nadir olarak saptand 1 (13).

Yapılan başka bir çalışmada ise, Şubat $2005^{\text {'de al- }}$ kollü içkiler üzerinden alınan özel tüketim vergisinin artırmasıyla özellikle şarapta vergi yükü çok ağırlaşmış ve tersine bir süreç islemeye başlamıştır. Şaraptaki söz konusu vergi yükünün şarap severler kadar üzüm ve şarap üreticileri ile turistik otelleri ve eğlence yerlerini de olumsuz etkilemesi kaçınılmaz bir olgu olup; halk arasında merdiven altı üretim ve tezgah altı satış olarak tabir edilen olası kayıt dışı ekonomi ise olayın başka bir boyutunu oluşturmaya başlamıştır (14).

Adli olgu niteliğinde olan metanol zehirlenmesinin hem adli muayenesinin yapılması hem de olay yerinin detaylı bir şekilde araştırılması gerekmektedir (15). Sonuç olarak, ani görme kaybıyla polikliniğe başvuran genç ve orta yaştaki hastalarda içki alımı öyküsü sorgulanmalı ve hasta toksikolojik açıdan da mutlaka değerlendirilmelidir. Ayrıca, metabolik asidoza yol açarak ölüm riski taşıdığından hastanın öyküsü ve muayenesinin iyi yapılması, mutlaka metanol zehirlenmesi akla getirilmeli ve adli mercilere bildirilmelidir.

\section{Kaynaklar}

1. Yaycı N, Ağrıtmış H, Turla A, Koç S. Fatalities due to methyl alcohol intoxication in Turkey: an 8-year study. Forensic Science International 2003; 131(1): 36-41.

2. Ryu J, Lim KH, Ryu DR, Lee HW. Two cases of mehyl alcohol intoxication by sub-chronic inhalation and dermal exposure during aluminium CNC cutting in a small-sized subcontracted factory. Ann Occup Environ Med 2016 Nov 15; 28:65

3. Liesivuori J,Savolainen H. Methanol and formic acid toxicity- biochemical mechanisms. Pharmacol Toxicol 1991; 69:157-163.

4. Barceloux DG, Bond GR, Krenzelok EP, Cooper H,Vale JA. American Academy of Clinical Toxicology practice guidelines on the treatment of methanol poisoning. J Toxicol 2002; 40:415-446

5. Sanae1-Zadeh H, Zamani N, Shadnia S. Outcomes of visual disturbances after methanol poisoning. Clinical Toxicol 2011;49:102-107

6. Zakharov S, Pelclova D, Diblik P. Long-term visual damage after acute methanol poisonings: longitudinal cross-sectional study in 50 patients. Clin Toxicoll(Phila) 2015; 53: 884-892.

7. Desai T, Sudhalkar A, Vyas U, Methanol poisoning: predictors of visual outcomes. JAMA Ophthalmol. 2013;131:358-364.

8. Hovda KE, Hunderi OH, Tajfjord A-B, Methanol outbreak in Norway 2002-2004: epidemiology, clinical features and prognostic signs.. Journal of Internal Medicine 2005;258:181-190.

9. Paasma R, Hovda KE, Moghaddam HH. Risk factors related to poor outcome after methanol poisoning and the relation between outcome and antidotes-a multicenter study. Clinical Toxicology.

10. Bergeron R, Cardinal J, Geadah D. Prevention of methanol toxicity by ethanol theraphy. N Engl J Med 1982; 307:1528.

11. Burns MJ, Graudins A, Aaron CK, McMartin K, Brent J. Treatment of methanol poisoning with intravenous 4-methylpyrazole. Ann Emerg Med 1997; 30:829-832.

12. Zakharov S, Pelclova D, Navratil T, Belacek J. Fomepizole versus ethhanol in the treatment of acute methanol poisoning: Comparison of clinical effectiveness in a mass poisoning outbreak. Clin Toxicol (Phila) 2015; 53:797-806.

13. Kurtas Ö, Imre KY, Ozer E, Can M, Birincioglu İ, Butun C, Kirci GS, Yildirim A, Kiyak S, Yilmaz S. The evaluation of deaths due to methyl alcohol intoxication. Biomedical Research 2017; 28 (8): 3680-3687.

14. Pınar YG. Tekirdağ ili Şarkoy ilçesinde şarap işletmeleri ile üzüm üreticilerinin çeşit seçimlerini etkileyen faktörlerin karşılaştırmalı analizi. (2008), Yüksek Lisans Tezi; Namık Kemal Üniversitesi Fen Bilimleri Enstitüsü, Tekirdağ.

15. Yaycı N, İnanıcı MA. Metil alkol (metanol) zehirlenmesi. Türkiye Klinikleri J Foren Med 2005;2(3):101-108. 